\title{
Ship's doctor qualifications: a response to the German recommendations
}

\section{Eilif Dahl, Suzanne Stannard}

Department of Occupational Medicine, Haukeland University Hospital, The Norwegian Centre for Maritime Medicine, Bergen, Norway

The Maritime Labour Convention 2006 (MLC 2006) reiterates an old rule that ships with more than 99 persons on board in international waters must carry a doctor, but it does not say anything about the necessary qualifications for that physician [1]. There is little published evidence as to the type and number of cases that ship's doctors are required to manage and the procedures that they need to perform - however we do know that whatever can happen on land will eventually occur at sea. While medicine is medicine no matter where it is practiced, what really makes the role of the ship's doctor unlike that of a general practitioner or emergency physician on land is the lack of certain medications and equipment and the remote location when the ship is not in port. So the ideal ship's doctors should know 'everything', which means that the more they know and can do, the better qualified they will be for practicing cruise medicine.

Although few cruise vessels have been registered in the United States, American and English-speaking passengers have traditionally dominated the cruise market. In the early 1990s the American College of Emergency Physicians (ACEP) formed a Section for Cruise Ship and Maritime Medicine and quickly created "Health Care Guidelines for Cruise Ship Medical Facilities" to improve conditions for passengers, crew and medical staff on board [2]. Decided by consensus among the ACEP Section members, the ACEP Guidelines were at first strongly opposed by the cruise industry, but after cooperation and many revisions they are now accepted by the Cruise Lines International Association (CLIA), an interest organisation that comprises all the world's major cruise lines [3]. Hence, the 2014 version of the ACEP Guidelines can be regarded as the minimum requirements for international cruise medicine today. They cover not only the qualification, experience, certifications and skills of ship's doctors and nurses, but also the following subjects: medical facility, clinical practice, documentation, equipment, pharmacy, infection control, imaging, medico-legal practice, patient feedback and contingency medical plans. The ACEP Guidelines recommend that ship's doctors have at least 3 years post-graduate experience in general and emergency medicine and appropriate life-saving courses, including Advanced Cardiac Life Support (ALS/ACLS), Advanced Paediatric Life Support (APLS/PALS) and from January 2017 also Advanced Trauma Life Support (ATLS) [4].

In recent years the number of cruise ships catering mainly to German-speaking passengers has increased markedly and thus the demand for German-speaking doctors is growing. Following requests for guidance from German doctors, the German Maritime Medicine Association (Deutsche Gesellschaft für Maritime Medizin = DGMM) published in May 2013 its position on the qualification and training of cruise ship doctors [5], and in an interesting recent article, Seidenstücker and Neidhardt [6] presented an English version of DGMM's recommendation and discussed its content. The DGMM recommendation states basic qualifications and propose a detailed 80-h introduction course to prepare for health care on ships.

However, not many physicians who consider going to sea for the first time have already decided that this is the career for them. Many do it as a side line to their main occupation, many as a 'career break'. They are hardly motivated for a long and comprehensive training course for a short time at sea. There is a delicate balance between interesting and overwhelming. An introduction course should not be overloaded with less relevant information, but strictly focus on 'need-to-know now' material.

What do doctors really need to know before sign-on?

First, they must be made aware of what makes a person, including the doctor, medically fit to pass a seafarer's examination and mentally suitable to function in the semiclosed, strict hierarchy of the ship. And then they need to be 
made familiar with the basics of the ship's doctor's various roles aboard: as a seafarer and officer, as the physician in charge of all medical issues aboard, both as the primary care and emergency care provider for all passengers and crew, and as the medical head of public health. These issues can be covered in less than three hours of lectures by an experienced ship's doctor.

Many of the subjects listed in the DGMM Recommendation under Basics and Maritime Specialties only need to be mentioned briefly because topics like introduction to ship construction, ship operation and ship organisation, international regulations, multicultural crew issues, dangerous goods, waste disposal and environmental issues, substance abuse, sexual harassment, emergency codes, action plans, cooperation and communication on board, ship safety, security plans and roles, abandon ship/lifeboat operations, survival at sea (drowning, seasickness, hyperthermia) and 'crowd and crisis management' are dealt with ad nauseam during more than $30 \mathrm{~h}$ of mandatory training. This is usually facilitated by the cruise company within their generic introduction training for all new to sea staff and most of the training has to be completed within the first 2 weeks aboard [7]. None of this is specific to the ship's doctor. There is really no good reason to get into details before sign-on; about $2 \mathrm{~h}$ should be sufficient instead of more than $20 \mathrm{~h}$ recommended by DGMM $[5,6]$.

Furthermore, what the ship's doctor in spe must know before sign-on about subjects like taxes and insurance, vaccinations and prophylaxis, travel and tropical medicine, radiation protection, handling of dead bodies etc., can also be covered in short, to-the-point lectures, each lasting only a few minutes. Also a seemingly ship-specific condition like prevention and treatment of seasickness can be effectively covered in minutes, while discussing the various side effects from anti-nausea medication brought on board by passengers may take a little longer. Further learning in these areas is ongoing as part of the ship's doctor role.

Most common, non-serious conditions can be dealt with aboard the same way as on land, but with particular focus on relieving discomfort and stress of vacationing passengers and ensure that ill crew members can return to work at full capacity as soon as possible.

Pre-sea preparation for dealing with life-threatening emergencies is, however, a different matter. Cruise vessels go all over the world and are often way outside helicopter range. The ship's doctors must therefore take care of all kinds of complicated medical matters alone - without help from modern shore-side facilities for days or weeks. As opposed to land-based practices, qualified specialist assistance is not just a phone call and/or ambulance ride away. Providing advanced life support over extended periods of time will therefore be necessary. Since the ACEP
Guidelines, now valid for all CLIA members, recommend ACLS, PALS and ATLS, a preparatory course should include internationally accepted certification in all these subjects [4]. Otherwise such certification must be achieved prior to sign-on somewhere else, which is impractical and costly. The various life support certifications provide a working platform for dealing with most life-threatening emergencies aboard, but the introduction course should further concentrate on how to best use the limited resources available on board while waiting for safe evacuation and transfer to definitive treatment. Lectures on state-of-the-art hospital treatment and fancy procedures that cannot be done aboard are of little value and clearly a waste of precious course time.

Attention needs to be paid to economic and safety consequences of evacuation and repatriation options as well as benefits and risks of helicopter transfer, boat transfer and ship diversion. How does a ship's doctor assess medical care in a port and therefore the benefits of landing a patient, or not? Is the patient fit to fly to a different location on land capable of appropriate medical care or repatriation home for ongoing care?

Two other subjects may need some special attention before sign-on:

Forensics. There is now increased attention on rape and violent crime on ships. An introduction course should emphasize that all potential crime must be properly reported and investigated, but be limited to the doctor's proper treatment and care of victims, including use of evidence collection kits. The cruise lines, according to ACEP's Guidelines, must ensure that at least one clinical staff member has completed recognized training [4], so they offer an internet course for preparation and certification to be done aboard by self-study during the first contract.

Public health. It is imperative to smooth running of the vessel that the ship's doctor knows as much as possible in advance about how to prevent and handle outbreaks of infectious diseases aboard, including routines for hand washing, disinfection and isolation, and how to correctly report to and deal with port health authorities before and during outbreaks. Missing an index case and trying to learn during an ongoing outbreak can have grave consequences and should be avoided. Therefore practical advice on these subjects should be presented already during an introduction course.

Ultimately, it is the companies' responsibility to ensure that the new doctors are made familiar with all available medications and equipment on board prior to sailing or during a handover period and to provide all obligatory safety training to the newcomers during their first few weeks of working [7]. The companies should also make certain that a new doctor share duties with a veteran senior doctor. If the line has only one-doctor ships, there must be ample overlap between the doctor who is leaving and the new one 
- who should be working with the most experienced ship's nurse(s). As doctors we never stop learning and this is no different at sea. If further skills are thought to be 'essential' within the first year/before promotion these could be gained and documented in a competency based programme once the doctor has started their time at sea.

In summary, we agree with DGMM that some sort of recognized, assessed and documented competencies for ship's doctors is essential to ensure high quality of care for passengers and crew alike. We are in full support of an agreed and equivalent level of qualification for all ship's doctors, regardless of where that ship is registered, where she is sailing and the nationality of crew and passengers. This will also give a much needed sense of professionalism to cruise medicine - for too long perceived by many as an easy life for vacationing doctors and for those who can't cut it in the real world anymore - or choose not to. How the qualifications are gained is a different issue and yes, any internationally agreed consensus will need to be incorporated into the local training system. However, a 3-week-course taken before ever stepping on board seems unnecessary and restrictive from a time and financial perspective. The course curriculum recommended by DGMM can be improved by including certification in mandatory courses of ACLS, PALS and ATLS. Much of the general information about personal safety and security, as well as life aboard in general, will be covered at a company level during compulsory courses for all new crew before boarding and/or during their first 2 weeks aboard. Hence, short preparatory remarks on these issues will suffice as pre-sea preparation. Lectures and practical training sessions should be limited to ship-related 'need-to-know now' material and comprise only procedures that can be done with medication and equipment available on the ships.

\section{CONFLICT OF INTEREST}

The authors have worked for different cruise lines as ship's doctors and medical consultant (ED)/medical director (SS). ED has lectured during one of the German courses mentioned in the text.

\section{REFERENCES}

1. Maritime Labour Convention 2006. Title 4. Regulation 4.1. http://www. mlc2006.com/the_convention/title4/4_1(Accessed 11 February 2015).

2. American College of Emergency Physicians. http://www.acep.org (Accessed 09 February 2015).

3. Cruise Lines International Association (CLIA). Policies. Medical facilities. http://www.cruising.org/regulatory/policies/medical-facilities (Accessed 09 February 2015).

4. American College of Emergency Physicians. Health Care Guidelines for Cruise Ship Medical Facilities: Revised July 2014. http://www. acep.org/Physician-Resources/Clinical/Health-Care-Guidelines-forCruise-Ship-Medical-Facilities (Accessed 09 February 2015).

5. Deutsche Gesellschaft für Maritime Medizin. Empfehlung für die Qualifikation von Schiffsärzten. www.maritimemedizin.de/ Publikationen/leitlinien/Schiffsarztqualifikation-Empfehlung\%20 Endfassung.pdf (Accessed 09 February 2015).

6. Seidenstücker KH, Neidhardt S. Qualification of ship doctors: a German approach. Int Marit Health 2014; 65: 181-186.

7. Standards of Training, Certification and Watchkeeping (STCW-95). Training Requirements for Existing and New Mariners. http://www. stcw.org/training.html (Accessed 11 February 2015). 